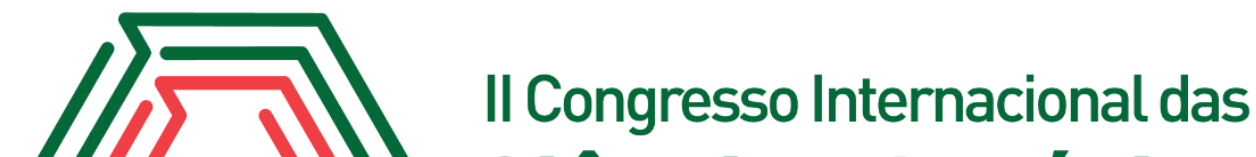 Ciências Agrárias COINTER - PDVAgro 2017
}

\section{COMPOSIÇÃO CENTESIMAL DO BAGAÇO DA ALGA Gracilaria birdiae CULTIVADOS EM RIO DO FOGO -RN}

Apresentação: Pôster

Beatriz Cristina Lopes ${ }^{1}$; Andréia Amanda Bezerra Jácome ${ }^{2}$; Vanessa Clarice Fernandes Alves ${ }^{3}$; Ivanilson de Souza Maia ${ }^{4}$

\section{Introdução}

As algas possuem grande relevância nutricional tanto para os seres humanos e animais como para organismos aquáticos (McHUGH, 2002 e 2003), são fontes de proteína, vitaminas, minerais e fibras, por isso já são bem empregadas indústrias alimentícia, farmacêutica, têxtil, cosmética e de fertilizantes (GRESSLER et al., 2011).

A Gracilaria birdiae é uma alga comestível que ocorre nos bancos naturais da costa nordestina, em especial no Ceará, Rio Grande do Norte e Paraíba, vem sendo cultivada em módulos flutuantes, por comunidades costeiras, como forma de preservação ambiental e agregação de valor econômico (SIMÕES, 2009; VIDOTTI; ROLLEMBERG, 2004). Historicamente, as algas arribadas são coletadas na beira da praia por toda costa.

Acidade de Rio do Fogo possui uma associação de mulheres que cultivam macroalgas, transformam-na em farinha e pó, para a fabricação de cosméticos e alimentos que serve como alternativa para geração de renda da comunidade.

Este trabalho tem como objetivo apresentar a composição centesimal do bagaço da alga Gracilaria birdiae, cultivada pela Associação das Maricultoras de Algas de Rio do Fogo - AMAR, na cidade de Rio do Fogo localizada no Rio Grande do Norte.

\section{Fundamentação Teórica}

As macroalgas são caracterizadas por serem ricas em proteínas e pobres em lipídios, além de

\footnotetext{
${ }^{1}$ Graduação em Engenharia de Pesca, Universidade Federal Rural do Semi-árido, lopesbc.engenhariadepesca@gmail.

${ }^{2}$ Pós-graduação em Produção Animal, Universidade Federal Rural do Semi-árido, amandabjacome@gmail.com

${ }^{3}$ Pós-graduação em Produção Animal, Universidade Federal Rural do Semi-árido, vanessaclaricefa@gmail.com

${ }^{4}$ Doutorado, Universidade Federal Rural do Semi-Árido, ivanilson.maia@ufersa.edu.br
} 
possuir valores altos de fibras alimentares sendo a principal fonte de exploração de Ágar - um ficocolóide de alto valor econômico - consumidos em larga escala, em muitos países, principalmente, pela indústria alimentícia (PEREIRA, 2010).

Nos últimos anos as algas tiveram um grande destaque na alimentação humana como ótima fonte alternativa, devido aos altos valores de proteínas, fibras e baixos valores de lipídios que eles apresentam, sendo assim alvo de muitas pesquisas cientificas (FLEURENCE et al., 2012).

\section{Metodologia}

As algas foram coletadas na Associação das Maricultoras de Algas de Rio do Fogo e levadas para laboratório da Universidade Federal Rural do Semi-Árido, no qual passou por processo de pesagem, lavagem com água doce, trituração e adição de $250 \mathrm{ml}$ de água, pesagem e separação do extrato, parte liquida e sólida.

Os sólidos foram levados para as análises de umidade, determinada pela perda de peso da amostra em estufa regulada a $105^{\circ} \mathrm{C}$ até obtenção de peso constante (AOAC, 2011); Cinzas, obtidas por incineração de uma quantidade conhecida da amostra, em mufla a $550^{\circ} \mathrm{C}$, até obtenção de peso constante (AOAC, 2011); Proteínas, dosada pelo método Kjedahl, que consiste na determinação do nitrogênio total. Para converter o resultado em proteína bruta foi utilizado o fator 6,25 (AOAC, 2011); Lipídeos Totais, extraídos a frio pelo método de Soxhlet, utilizando a extração com hexano, lavagem do resíduo (AOAC, 2011) e Carboidratos - Calculado por diferença.

\section{Resultados e Discussões}

Foram pesados um quilo da alga no qual rendeu 510 gramas de extrato e 530 gramas de sólido (Figura 1).

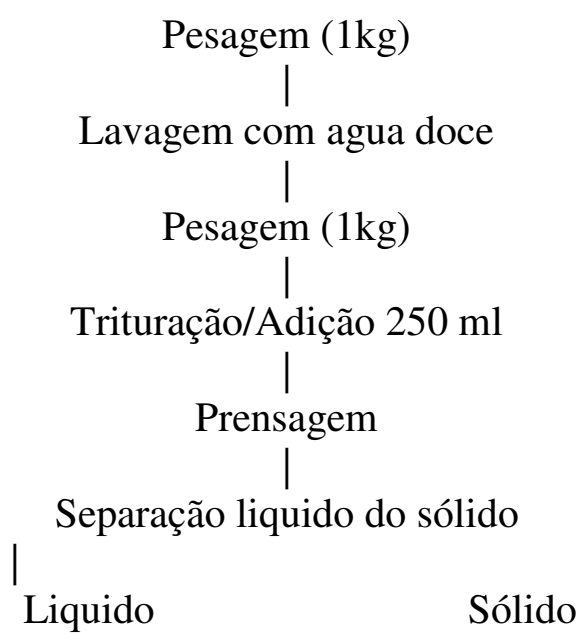




\section{$510 \mathrm{~g} \quad 530 \mathrm{~g}$ \\ Figura 1. Rendimento Gracilaria birdiae}

A composição centesimal aproximada (umidade, cinzas, lipídeos e gordura) dos dados obtidos em triplicata da alga Gracilaria birdiae encontra-se descrita na Tabela 1. Os resíduos sólidos contêm, respectivamente, a umidade como componente principal $(89,09 \%)$, seguida da proteína $(5,91 \%)$, carboidrato $(0,16 \%)$, cinzas $(4,48 \%)$ e lipídeos $(0,37 \%)$.

Tabela 1: percentual médio dos valores obtidos na análise da alga Gracilariabirdiae.

\begin{tabular}{lcccc}
\hline \multicolumn{5}{c}{ Composição centesimal Gracilariabirdiae } \\
\hline Análises & $\begin{array}{c}\text { Presente } \\
\text { trabalho }\end{array}$ & $\begin{array}{c}\text { Batista* } \\
(2008)\end{array}$ & $\begin{array}{l}\text { Pires * } \\
(2012)\end{array}$ & $\begin{array}{c}\text { Rebouças ** } \\
(2013)\end{array}$ \\
Umidade & $89,09(\%)$ & $10,3(\%)$ & $15,25(\%)$ & $17,6(\%)$ \\
Cinzas & $4,48(\%)$ & $31,9(\%)$ & $5,58(\%)$ & $14,1(\%)$ \\
Proteína & $5,91(\%)$ & $12,11(\%)$ & $12,62(\%)$ & NR*** \\
Lipídios & $0,37(\%)$ & $0,72(\%)$ & $0,11(\%)$ & $0,35(\%)$ \\
\hline
\end{tabular}

*Utilização da alga inteira e seca ao sol antes das análises.

** Utilização do bagaço da alga com pré secagem ao sol antes das análises.

***NR- Não informado.

GONÇALVES (2011) diz que o pescado tem como principal componente a água, podendo variar de $60 \%$ a $85 \%$, conforme a espécie, época do ano, idade, sexo e estado nutricional de cada organismo. Os valores da determinação de umidade variam significativamente dos encontrados na bibliografia, 10,3\% segundo BATISTA (2008), 15,25\% para PIRES et al (2012) e 17,6\% REBOUÇAS (2013), em função da utilização da alga, inteira e desidratada, com secagem ao sol, pelos autores citados.

Nota-se na tabela 1 , que com a utilização do bagaço ocorre uma diminuição na quantidade de proteínasde 13,5 \% BATISTA (2008) e 12,62 \% PIRES et al (2012) para 5,91\%. Mesmo com essa diferença é um valor proteico considerável.

Os valores para cinzas obtidos $(4,48 \%)$ assemelham-se ao apresentado apenas por PIRES et al (2012), 5,58\%. E a quantificação de lipídeos 37\% se adequa ao encontrado por REBOUÇAS (2013), 0,35\%. Dessas formas estes,macronutrientes não se alteram quando separado o extrato.

A medida que ocorre a separação do extrato a partirdo bagaço,a gordura $(0,37 \%)$ no bagaço de Gracilaria birdiae não diminui quando comparado com Rebouças (2013). 


\section{Conclusões}

Conclui-se que o bagaço da alga marinha Gracilaria birdiae cultivados no município de Rio do Fogo possui valor proteico significativo e com baixo teor de gordura. Portanto, é importante que seja explorado o potencial desses nutrientes existentes.

\section{Referências}

AOAC - Official Methods of Analysis of AOAC International, 18th ed., AOAC International, Gaithersburg, MD (USA), Official Method for Fish and Other marine Products, chap. 35, 1-36 p., 2011.

BATISTA, S. I. M. 2008. Efeito da substituição da farinha de peixe por farinha de algas Gracilaria sp. e Ulva rigida no crescimento e nos parâmetros metabólicos da dourada (Sparusaurata). Dissertação Mestrado. Faro. Universidade do Algarve. Faculdade de Engenharia de Recursos Naturais. 72p.

FLEURENCE, J., MORANÇAIS, M., DUMAY, J., DECOTTIGNIES, P., TURPIN, V., MUNIER, M., BUENO, N.G.P. J. What are the prospects for using seaweed in human nutrition and for marine animals raised through aquaculture?,Trends in Food Science \& Technology,2012.

GRESSLER, V.; YOKOYA, N. S.; FUJII, M.T.; COLEPICOLO, P.; FILHO, J. M.; TORRES R. P.; PINTO, E. Lipds, fatty acids, protein, amino acid and ash contents in four Brazilian red algae species. FoodChemistry, October. 2009.

MCHUGH, D. 2002. Perspectivas para laproducción de algas marinas enlos países endesarrollo. FAOCirc. Pesca, 968, Roma. 30 p.

MCHUGH, D. 2003. A guide to the seaweed industry. FAO Fish. Tech. Pap, 441, Roma. 105 p.

SIMÕES, M. A. 2009. Estudo de cultivo e de biomoléculas da macroalga.Gracilariabirdiae (Rhodophyta, Gracilariales). Dissertação de Mestrado. UFRPE. Recife, 54p.

VIDOTTI, E. C.; ROLLEMBERG, M. C. 2004. Algas: da economia nos ambientes aquáticos à bioremediação e à química analítica. Química Nova, 27, 1 .

REBOUÇAS, R. F. C. 2013. Estudo do Teor de Lipídios e Avaliação dos resíduos das Algas Marinhas: Gracilariacaudata, Gracilariabirdiae, Gracilariadomingensis para preparação de Biodiesel eBiofertilizante. Dissertação de Mestrado. UERN. Mossoró, 79 p.

PEREIRA, D. C. Variação no conteúdo proteico e pigmentar em variantes cromáticas deGracilariadomingensis nas populações naturais de rio de fogo - RN - Brasil. Mestrado UFRN,74p. 2009.

PIRES et al. 2012. Caracterização físico-química da macroalga Gracilariabirdiae. Livro de resumos: $52^{\circ}$ Congresso Brasileiro de Química. Resumo Expandido. Recife. 